Boise State University ScholarWorks

Materials Science and Engineering Faculty

Publications and Presentations

Department of Materials Science and Engineering

8-26-2015

\title{
Carbon Dioxide Sorption in a Nanoporous Octahedral Molecular Sieve
}

Izaak Williamson

Boise State University

Eric B. Nelson

Boise State University

Lan Li

Boise State University 


\title{
Carbon Dioxide Sorption in a Nanoporous Octahedral Molecular Sieve
}

\author{
Izaak Williamson \\ Department of Materials Science and Engineering \\ Boise State University \\ Boise, ID \\ Eric B. Nelson \\ Department of Materials Science and Engineering \\ Boise State University \\ Boise, ID \\ Lan Li \\ Department of Materials Science and Engineering \\ Boise State University \\ Boise, ID
}

\begin{abstract}
We have performed first-principles density functional theory calculations, incorporated with van der Waals interactions, to study $\mathrm{CO}_{2}$ adsorption and diffusion in nanoporous solid - OMS2 (Octahedral Molecular Sieve). We found the charge, type, and mobility of a cation, accommodated in a porous OMS-2 material for structural stability, can affect not only the OMS-2 structural features but also $\mathrm{CO}_{2}$ sorption performance. This paper targets $\mathrm{K}^{+}, \mathrm{Na}^{+}$, and $\mathrm{Ba}^{2+}$ cations. First-principles energetics and electronic structure calculations indicate that $\mathrm{Ba}^{2+}$ has the strongest interaction with the OMS-2 porous surface due to valence electrons donation to the OMS-2 and molecular orbital hybridization. However, the Ba-doped OMS-2 has the worst $\mathrm{CO}_{2}$ uptake capacity. We also found evidence of sorption hysteresis in the K- and Nadoped OMS-2 materials.
\end{abstract}

\section{Introduction}

The capture and storage of carbon dioxide from fossil fuel power plant emissions are important tasks that scientists are facing today [1]. Research has shown that adsorption of $\mathrm{CO}_{2}$ onto solids can be an effective method for selectively separating $\mathrm{CO}_{2}$ from flue gases [2-7]. This method has a lower parasitic energy than current aqueous technologies and could potentially replace them [6,8-11]. Porous solids, including zeolite membranes, molecular sieves, and metal organic frameworks are preferential for gas adsorption because of their high surface areas [4-7,1218]. These materials can have a variety of pore geometries and sizes which can affect the $\mathrm{CO}_{2}$ adsorption and desorption properties [6,19-22]. There is also the potential for further "tuning" of the properties by chemical substitution making these great candidates for 'materials-by-design' applications [5,6,9,18]. Extensive computational studies confirm the need to explore the structural behavior of $\mathrm{CO}_{2}$ with an analysis of relative van der Waals (vdW) bonding for metal organic framework candidates [2,6,17,18,23,24]. However, many of these materials experience hysteresis in their adsorption and desorption processes which increase the parasitic energy. Understanding the mechanism behind this hysteresis is necessary for advancing these materials into industrial applications.

Manganese dioxide $\alpha-\mathrm{MnO}_{2}$, referred to as OMS-2, is a nanoporous octahedral molecular sieve (OMS) that experiences $\mathrm{CO}_{2}$ hysteresis $[21,22,25]$. The framework of the OMS-2 structure is made up of edge-sharing $\mathrm{MnO}_{6}$ octahedra that form relatively small $(1 \times 1)$ and large $(2 \times 2)$ tunnels. These tunnels act as one-dimensional "traps" where $\mathrm{CO}_{2}$ adsorption and molecular sieving processes can occur[2]. The OMS-2 structure requires the presence of cations inside the large $(2 \times 2)$ tunnels that act as a means of structural support. Common dopants for this system 
include $\mathrm{K}^{+}, \mathrm{Ba}^{2+}, \mathrm{Na}^{+}$, and $\mathrm{Pb}^{4+}[21,22,25]$. Previously, we found that adding $\mathrm{K}^{+}$ions to the $(2 \times 2)$ tunnels leads to hysteresis looping in the adsorption and desorption isotherms [26]. The onset of hysteresis only occurs at experimental partial pressures exceeding $7 \mathrm{bar}(700 \mathrm{kPa})$. This study revealed the importance of understanding the $\mathrm{CO}_{2}$ sorption mechanism and the physical factors involved.

Density functional theory (DFT) calculations with van der Waals forces revealed $\mathrm{CO}_{2}$ sorption on K-doped OMS-2, known as cryptomelane [27]. We investigated the diffusion of $\mathrm{CO}_{2}$ through the $(2 \times 2)$ tunnel and found that the $\mathrm{K}^{+}$ dopant acts as a 'gate keeper' blocking the path of the $\mathrm{CO}_{2}$ molecules. When the concentration of $\mathrm{CO}_{2}$ is increased (>7 bar pressure), the activation energy barrier for the $\mathrm{CO}_{2}$ to bypass $\mathrm{K}^{+}$reduces significantly. This allows the $\mathrm{CO}_{2}$ to become trapped behind $\mathrm{K}^{+}$, hindering desorption. More recently, we compared the sorption behavior of Ba-doped OMS-2, known as hollandite, to the results from cryptomelane [9]. The higher-charge cation $\mathrm{Ba}^{2+}$ was found to perform worse in the $\mathrm{CO}_{2}$ sorption than the lower-charge cation $\mathrm{K}^{+}$. This could be attributed to the stronger binding energy of $\mathrm{Ba}^{2+}$ with the OMS-2 porous surface.

In further studying the cation effect, this paper compares $\mathrm{K}^{+}, \mathrm{Na}^{+}$, and $\mathrm{Ba}^{2+}$ cations in the OMS-2, including their structural features, interactions with the pore surface, and $\mathrm{CO}_{2}$ adsorption and diffusion mechanisms. These studies identify key factors controlling $\mathrm{CO}_{2}$ uptake capacity and help develop high-performance porous solids for carbon capture and storage.

\section{Computational Methods}

The Vienna ab-initio Software Package (VASP)[28] was performed within density functional theory (DFT) to conduct all structural, energetic, and electronic structure calculations. The spin-polarized generalized gradient approximation (GGA) was used within the Perdew Burke Ernzerhoff formalism revised for solid systems (PBEsol)[29]. The plane-wave basis sets were expanded using projector-augmented wave (PAW) pseudopotentials[30,31] to a cutoff energy of $400 \mathrm{eV}$. To account for the d-orbitals of Mn, the GGA+U approach of Liechtenstein et al [32] was employed, where an effective on-site Coulomb potential (U) of $2.8 \mathrm{eV}$ and an exchange potential $(\mathrm{J})$ of $1.2 \mathrm{eV}$ were applied to the system. The Brillouin zone integration was performed on a $6 \times 6 \times 6$ Monkhorst-Pack mesh. To account for Fermi surface broadening, a Gaussian smearing value of $0.05 \mathrm{eV}$ was applied. The Mn atoms have an antiferromagnetic interaction with magnetic moments of $\pm 4 \mu_{\mathrm{B}}$. [33,34] All relaxations of the lattice parameters and atomic positions were performed until residual forces were reduced to $0.01 \mathrm{eV} / \AA \AA$. In a previous study[34], we found that incorporating van der Waals (vdW) forces using the DFT-D2 approach of Grimme,[35] applied to the $\alpha-\mathrm{MnO}_{2}$ structure accommodating $\mathrm{K}^{+}$and $\mathrm{H}_{2} \mathrm{O}$, produced a binding energy very similar to that of the DFT calculation. The charge and dipole interactions were found to dominate in this system. Although, it has been shown that the electrostatic interactions dominate when $\mathrm{CO}_{2}$ is near a cation [36] and vdW interactions are prominent when $\mathrm{CO}_{2}$ is far from the cation (away from its equilibrium position) [37]. Nevertheless, we incorporated the vdW-DFT scheme in the energetic calculations to compare with DFT. In addition, we performed nudged elastic band method to confirm a transition state during $\mathrm{CO}_{2}$ diffusion in the OMS-2.

The unit cell of $\alpha-\mathrm{MnO}_{2}$ (with no cation) is $\mathrm{Mn}_{8} \mathrm{O}_{16}$ with calculated equilibrium lattice parameters, $a=9.702 \AA, b=$ $2.856 \AA$, and $c=9.685 \AA$. In order to accommodate the cations and $\mathrm{CO}_{2}$ molecules in the $(2 \times 2)$ tunnel, we tripled the unit cell along the $b$ axis. The $1 \times 3 \times 1$ supercell was found to be energetically favorable and was used to elongate the tunnels formed by the edge-sharing $\mathrm{MnO}_{6}$ octahedra. We used the cell of $\mathrm{XMn}_{24} \mathrm{O}_{48}$ (i.e. $\mathrm{X}_{0.04} \mathrm{MnO}_{2}$ ), where $\mathrm{X}=\mathrm{K}$, $\mathrm{Na}$, or $\mathrm{Ba}$, and varied $\mathrm{CO}_{2}$ concentration in the cell to provide insight into the $\mathrm{CO}_{2}$ sorption mechanism.

\section{Results and Discussion}

\section{$\underline{\mathrm{K}} \pm \underline{\mathrm{Na}^{ \pm}} \stackrel{ \pm}{\text { and } \mathrm{Ba}^{2+}} \stackrel{\underline{2+}}{\text { Cations }}$}

The equilibrium parameters of undoped $1 \times 3 \times 1 \alpha-\mathrm{MnO}_{2}$ supercell (i.e. with no cation) are a $=9.702 \AA, \mathrm{b}=8.568 \AA$, $\mathrm{c}=9.685 \AA$. The dopants were then added manually to the tunnel centers and relaxed again to determine their structural effects. Table 1 reveals that the calculated cell volume increases by $0.30 \%$ and $0.32 \%$ in the presence of $\mathrm{K}^{+}$and $\mathrm{Ba}^{2+}$, respectively. This increase is caused by enlarging the cell size in the $c$ direction. The cell sizes in the other two directions remain relatively unchanged from the undoped cell. In contrast, the presence of $\mathrm{Na}^{+}$shrinks the cell volume by $0.17 \%$, as a result of reducing the cell size in the $a$ direction. As seen in Fig. 1 , we found two highsymmetry sites along the $(2 \times 2)$ tunnel: Sites A and B. The lower-energy position (i.e., the more stable) for the 
This is an author-produced, peer-reviewed version of this article. The final, definitive version of this document can be found online at Journal of Physics D: Applied Physics, published by IOP Publishing. Copyright restrictions may apply. doi: 10.1088/00223727/48/33/335304

cation is Site $\mathrm{A}$, which neighbors with eight oxygen atoms. The $\alpha-\mathrm{MnO}_{2}$ cell volume increase in the presence of $\mathrm{K}^{+}$ and $\mathrm{Ba}^{2+}$ causes the slightly longer distances between the cation and its closest $\mathrm{Mn}$ and $\mathrm{O}$ than those for $\mathrm{Na}^{+}$(Table 1).

To analyze the cation $-\alpha-\mathrm{MnO}_{2}$ interaction, the binding energy $E_{b}$ of a cation is defined as:

$$
E_{b}=\frac{E_{t o t, \text { doped }}-E_{\text {tot }, \text { undoped }}-n E_{\text {dopant }}}{n}
$$

where $E_{\text {tot,doped }}$ and $E_{\text {tot,undoped }}$ are the total energy of $\mathrm{Mn}_{24} \mathrm{O}_{48}$ doped with and without a cation, respectively. $E_{\text {dopant }}$ is the energy of an individual $\mathrm{K}, \mathrm{Na}$, or Ba atom, and $n$ is the number of cations in the cell.[9,34] $E_{b}$ between cation and $\alpha-\mathrm{MnO}_{2}$ is $4.48 \mathrm{eV} / \mathrm{K}^{+}, 4.18 \mathrm{eV} / \mathrm{Na}^{+}$, and $8.34 \mathrm{eV} / \mathrm{Ba}^{2+}$, indicating a strong interaction. $\mathrm{Ba}^{2+}$ donates more valence electrons to $\alpha-\mathrm{MnO}_{2}$, leading to much higher $E_{b}$ than that of $\mathrm{K}^{+}$and $\mathrm{Na}^{+}$. Interestingly, the same-charged cations $\mathrm{K}^{+}$and $\mathrm{Na}^{+}$also have slightly different $E_{b}$.

It is worth noting that during synthesis of these compounds, $\mathrm{H}_{2} \mathrm{O}$ molecules can be found to coordinate with the cation and hinder $\mathrm{CO}_{2}$ adsorption uptake [26,34]. However, in a previous experimental study of K-doped OMS-2, it has been shown that upon heating to $150^{\circ} \mathrm{C}$, the $\mathrm{H}_{2} \mathrm{O}$ can be removed without affecting the $\mathrm{K}^{+}$dopant [34]. This is likely due to the difference in binding energy between the $\mathrm{H}_{2} \mathrm{O}$ molecule $(0.39 \mathrm{eV})$ and the $\mathrm{K}^{+}$dopant $(>4 \mathrm{eV})$ in $\alpha$ $\mathrm{MnO}_{2}$ [34]. Given that the other cations investigated in this study have similar or greater binding energies than $\mathrm{K}^{+}$, it is reasonable to assume the same ease of $\mathrm{H}_{2} \mathrm{O}$ removal from their compounds as well.

Adding a cation to $\alpha-\mathrm{MnO}_{2}$ also reduces $\mathrm{Mn}^{4+}$ to $\mathrm{Mn}^{3+}$.[34,38] Our calculations showed that each donated electron is shared by several $\mathrm{Mn}$, resulting in non-integer charges on the $\mathrm{Mn}$. We calculated the electronic structures of undoped and doped $\alpha-\mathrm{MnO}_{2}$ and compared them to provide detailed insight into the cation effect on the molecular orbitals of the $\alpha-\mathrm{MnO}_{2}$. Fig 2(a) - (c) shows the DOS (density of states) of $\alpha-\mathrm{MnO}_{2}$ doped with $\mathrm{K}, \mathrm{Na}$, and $\mathrm{Ba}$, compared with the DOS of $\mathrm{K}, \mathrm{Na}$, and $\mathrm{Ba}$ individually. The Fermi energy is zero in each case. Undoped $\alpha-\mathrm{MnO}_{2}$ is a semiconductor with a band gap of $1.33 \mathrm{eV}$ (see the DOS of undoped $\alpha-\mathrm{MnO}_{2}$ in Fig 2(d)). In the presence of a cation, the conduction band of $\alpha-\mathrm{MnO}_{2}$ is shifted below the Fermi energy at zero due to the accumulated electrons from the cation, leading to the n-type conduction and the ionic characteristics of the cation $-\alpha-\mathrm{MnO}_{2}$ bonds. For $\mathrm{K}$ and Ba doping, molecular orbital hybridization also occurs on the higher energy level between $-13 \mathrm{eV}$ and $-12 \mathrm{eV}$, indicating the covalent characteristics of the cation $-\alpha-\mathrm{MnO}_{2}$ bonds. This feature explains the binding energy, $E_{b}$, difference for $\mathrm{K}^{+}$and $\mathrm{Na}^{+}$in $\alpha-\mathrm{MnO}_{2}$. Fig 2(d) combines the DOS curves of doped and undoped $\alpha-\mathrm{MnO}_{2}$. Cation doping can minimize the band gap of $\alpha-\mathrm{MnO}_{2}$. Ba doping provides the calculated band gap of $1.14 \mathrm{eV}$, smaller than $1.29 \mathrm{eV}$ with $\mathrm{K}$ doping. Experimentally, the band gap for cryptomelane, i.e. $\alpha-\mathrm{MnO}_{2}$ with $\mathrm{K}^{+}$, is $1.32 \mathrm{eV}$ [39], agreeing well with our calculations.

\section{$\underline{\mathrm{CO}}_{2}$ Sorption}

$\mathrm{CO}_{2}$ adsorption in the OMS-2 tunnel more greatly affects the structure of $\alpha-\mathrm{MnO}_{2}$ than cation doping does. Table 2 shows that this effect is larger for the K- and Ba-doped systems with cell volume increases of $1.00 \%$ and $0.97 \%$, respectively. The Na-doped system is the least affected with a cell volume increase of only $0.63 \%$. However, the $\mathrm{CO}_{2}$ adsorption enlarges the volume change by three times more than the cation-doped system without $\mathrm{CO}_{2}$.

Cations are distributed along the OMS-2 $(2 \times 2)$ tunnel. When $\mathrm{CO}_{2}$ diffuses in the tunnel and encounters a cation, there are three possible scenarios (Fig. 3). For different cations, we estimated an activation energy barrier for each scenario. The lower activation energy barrier represented the more favorable scenario for the cation.

- Scenario I: $\mathrm{CO}_{2}$ does not continue diffusing, and it remains in a stable position.

- Scenario II: $\mathrm{CO}_{2}$ continues diffusing, and it can bypass a cation.

- Scenario III: $\mathrm{CO}_{2}$ continues diffusing, and it can push a cation away.

With a low concentration of $\mathrm{CO}_{2}$ in the K-doped OMS-2 (averagely $\mathrm{KMn}_{24} \mathrm{O}_{48}$ with one $\mathrm{CO}_{2}$ molecule), $\mathrm{CO}_{2}$ is kinetically trapped in a position away from a $\mathrm{K}^{+}$cation with the equilibrium distance of $3.0 \AA$. Due to a high activation energy barrier of $\sim 6 \mathrm{eV} / \mathrm{CO}_{2}, \mathrm{CO}_{2}$ remains in the equilibrium position without further diffusion (Scenario I, 
Fig 3(a)). As the concentration of $\mathrm{CO}_{2}$ increases, the activation energy barrier minimizes to $0.13 \mathrm{eV} / \mathrm{CO}_{2}$ [26], smaller than a diffusion energy barrier of $0.37 \mathrm{eV}$ for a $\mathrm{K}^{+}$cation. These computational results suggest Scenario II (Fig 3(b)), where $\mathrm{CO}_{2}$ bypasses a $\mathrm{K}^{+}$cation to further diffuse along the OMS-2 tunnel when $\mathrm{CO}_{2}$ has a high concentration (averagely $\mathrm{KMn}_{24} \mathrm{O}_{48}$ with two or more than two $\mathrm{CO}_{2}$ molecules). The reduction in activation energy barrier indicates that at elevated $\mathrm{CO}_{2}$ partial pressures, the transition state becomes more energetically favorable [26].

In the Ba-doped OMS-2, the activation energy barrier for $\mathrm{CO}_{2}$ diffusion decreases from $6.87 \mathrm{eV} / \mathrm{CO}_{2}$ to $1.02 \mathrm{eV} / \mathrm{CO}_{2}$ due to the $\mathrm{CO}_{2}$ concentration increase, but the barrier is still higher than that in the K-doped OMS-2. It is not low enough to be overcome. Thus, $\mathrm{CO}_{2}$ is stuck in the optimum position with a distance of $\sim 3 \AA \AA$ (Scenario I). No further diffusion occurs. This mechanism suggests worse $\mathrm{CO}_{2}$ uptake performance of the Ba-doped OMS-2.

The cell volume of $\alpha-\mathrm{MnO}_{2}$ increases with the $\mathrm{K}$ and $\mathrm{Ba}$ doping, but it decreases with the Na doping. In addition, the $\mathrm{Na}-\alpha-\mathrm{MnO}_{2}$ binding energy is the smallest, compared to those for $\mathrm{K}^{+}$and $\mathrm{Ba}^{2+}$. These features imply a different $\mathrm{CO}_{2}$ sorption mechanism occurs in the Na-doped OMS-2. We estimated the adsorption energy of $\mathrm{CO}_{2}$ in the OMS-2 by modifying Equation (1) in order to study the cation effect on the $\mathrm{CO}_{2}$ adsorption performance. If the adsorption energy of $\mathrm{CO}_{2}$ is a positive value, adsorbing $\mathrm{CO}_{2}$ costs an energy penalty, i.e. an increase in the total energy of the system. If the adsorption energy of $\mathrm{CO}_{2}$ is a negative value, adsorbing $\mathrm{CO}_{2}$ is energetically favorable, i.e. a decrease in the total energy of the system. In comparison between the K- and Na-doped OMS-2, we obtained $0.89 \mathrm{eV} / \mathrm{CO}_{2}$ and $-0.61 \mathrm{eV} / \mathrm{CO}_{2}$, respectively. The negative and lower $\mathrm{CO}_{2}$ adsorption energy suggests that the Na-doped OMS-2 should display higher $\mathrm{CO}_{2}$ uptake capacity than the K-doped OMS-2. However, a large amount of $\mathrm{CO}_{2}$ uptake in the OMS-2 reduces the spaces available for additional $\mathrm{CO}_{2}$, leading to the adsorption energy increase. We found that the high concentration of $\mathrm{CO}_{2}$ in the Na-doped OMS-2 (e.g., $\mathrm{NaMn}_{24} \mathrm{O}_{48}$ with two or more than two $\mathrm{CO}_{2}$ molecules) causes the adsorption energy to increase from $-0.61 \mathrm{eV} / \mathrm{CO}_{2}$ to $0.83 \mathrm{eV} / \mathrm{CO}_{2}$. Therefore, increasing temperature or pressure is needed to facilitate the $\mathrm{CO}_{2}$ adsorption process.

After adsorption, $\mathrm{CO}_{2}$ diffuses in the OMS-2 tunnel until it encounters a $\mathrm{Na}^{+}$cation with an equilibrium distance of $3.81 \AA$ (Scenario I), longer than with a $\mathrm{K}^{+}$cation. The cation behaves as a "gate keeper" to block further $\mathrm{CO}_{2}$ diffusion. Considering Scenario II, as in the K-doping case, $\mathrm{CO}_{2}$ bypasses the $\mathrm{Na}^{+}$cation. It has to form an unstable transition configuration, where $\mathrm{CO}_{2}$ sits by the side of the cation, and the cation slightly shifts to the OMS-2 porous surface to give more space to $\mathrm{CO}_{2}$ (Fig. 3(b)). With a low concentration of $\mathrm{CO}_{2}$, the transition configuration experiences an activation energy barrier of $3.04 \mathrm{eV} / \mathrm{CO}_{2}$ for the Na-doped OMS-2, about three times smaller than that for the K-doped OMS-2. As the concentration of $\mathrm{CO}_{2}$ increases, the activation energy barrier reduces to 0.87 $\mathrm{eV} / \mathrm{CO}_{2}$, but it is still too high to overcome. Therefore, Scenario II is not kinetically favorable.

In Scenario III, $\mathrm{CO}_{2}$ pushes the cation along the OMS-2 tunnel axis (Fig. 3(C)). The energy required to displace the cation, which is calculated as the difference in total energy between the system where the cation is in its equilibrium position and that of the cation in the adjacent position, is referred to as the 'diffusion energy.' This mechanism requires a sufficiently low energy barrier for the cation. We estimated the diffusion energy barrier of $0.16 \mathrm{eV}$ for the $\mathrm{Na}^{+}$cation in the OMS-2 tunnel. Such a value can be easily overcome, and is much smaller than both the activation energy barrier for $\mathrm{CO}_{2}$ to bypass the $\mathrm{Na}^{+}$cation as well as the diffusion energy barrier for the $\mathrm{K}^{+}$cation. Research on porous materials exhibited that the cation is movable in the porous tunnels $[9,26,40,41]$. Our calculations indicate that Scenario III is more energetically favorable, where $\mathrm{CO}_{2}$ pushes the $\mathrm{Na}^{+}$cation to further diffuse along the OMS-2 tunnel.

Table 3 summarizes different $\mathrm{CO}_{2}$ sorption mechanisms in the OMS-2 with $\mathrm{K}$, Na, and Ba doping. Scenario I occurs in all three cases. After adsorption, $\mathrm{CO}_{2}$ is thermally activated to diffuse in the OMS-2 tunnel until it encounters a cation. For a $\mathrm{K}^{+}$cation, $\mathrm{CO}_{2}$ bypasses it to further diffuse along the OMS-2 tunnel (Scenario II). For a $\mathrm{Na}^{+}$cation, $\mathrm{CO}_{2}$ continues diffusing by pushing the cation (Scenario III). These scenarios are illustrated in Figure 3. For a $\mathrm{Ba}^{2+}$ cation, $\mathrm{CO}_{2}$ remains in an optimum position with no further diffusion. These mechanisms suggest a sorption hysteresis. The phenomenon of sorption hysteresis commonly occurs in gas molecule adsorption and desorption isotherms. This indicates that the path to adsorption of gas molecules by a porous host differs from that of desorption.

Even though it has the worst $\mathrm{CO}_{2}$ uptake capacity, the Ba-doped OMS-2 is expected to have the smallest hysteresis. Upon desorption (e.g., a pressure decrease) $\mathrm{CO}_{2}$ can easily exit the OMS-2 tunnel. In contrast, $\mathrm{CO}_{2}$ can diffuse farther in the OMS-2 tunnel by passing through a $\mathrm{K}^{+}$cation and pushing a $\mathrm{Na}^{+}$cation. These mechanisms require a 
This is an author-produced, peer-reviewed version of this article. The final, definitive version of this document can be found online at Journal of Physics D: Applied Physics, published by IOP Publishing. Copyright restrictions may apply. doi: 10.1088/00223727/48/33/335304

longer time to vacuum $\mathrm{CO}_{2}$ in the OMS-2 tunnel, yielding the phenomenon of sorption hysteresis. The Na-doped OMS-2 should have a slightly smaller hysteresis than the K-doped OMS-2. In Scenario II, upon desorption $\mathrm{CO}_{2}$ has to pass through the $\mathrm{K}^{+}$cation in reverse. This action costs an energy penalty and requires more time than the $\mathrm{Na}^{+}$ cation case, where $\mathrm{CO}_{2}$ can directly exit the tunnel with no need to pass any $\mathrm{Na}^{+}$cation. The computational prediction has been validated by our experiment, which will be published in another experimental paper soon. Our results suggest that the charge, size and mobility of cation accommodated in a porous material control the $\mathrm{CO}_{2}$ uptake capacity and sorption hysteresis.

\section{Conclusions}

We have performed first-principles quantum mechanical simulations, based on density functional theory incorporated with van der Waals interaction (DFT+vdW), to study cation effects on the OMS-2 structure and $\mathrm{CO}_{2}$ sorption. $\mathrm{K}^{+}$, $\mathrm{Na}^{+}$, and $\mathrm{Ba}^{2+}$ cations have to be accommodated in the OMS-2 tunnel for structural stability. The charge and type of the cation affect the OMS-2 structure where the $\mathrm{K}^{+}$and $\mathrm{Ba}^{2+}$ cations lead to a cell volume increase while the $\mathrm{Na}^{+}$ cation decreases the cell volume. Conversely, the like-charge $\mathrm{K}^{+}$and $\mathrm{Na}^{+}$cations have the smaller binding energies with the porous surface of the OMS-2 than the higher-charged $\mathrm{Ba}^{2+}$ cation. Besides the charge and type, cation mobility is also found to control the $\mathrm{CO}_{2}$ uptake capacity and sorption mechanism of OMS-2. The diffusion of adsorbed $\mathrm{CO}_{2}$ is hindered by the cations, which act as 'gatekeepers' blocking the $\mathrm{CO}_{2}$ diffusion. It traps $\mathrm{CO}_{2}$ within the OMS-2 leading to a sorption hysteresis. After adsorption, $\mathrm{CO}_{2}$ diffuses until it encounters a cation. Three possible mechanisms occur, depending on an activation energy barrier for further $\mathrm{CO}_{2}$ diffusion and cation mobility. Scenario I involves $\mathrm{CO}_{2}$ becoming kinetically trapped in an equilibrium position with no further diffusion. Scenario II is that $\mathrm{CO}_{2}$ bypasses the cation to further diffuse along the OMS-2 tunnel. Scenario III is that $\mathrm{CO}_{2}$ continues diffusing by pushing the cation away. In all three cation cases, Scenario I occurs. In the K- and Na-doped OMS-2, $\mathrm{CO}_{2}$ can diffuse further through Scenarios II and III, respectively. These mechanisms also suggest that the Ba-doped OMS-2 should have the smallest sorption hysteresis, followed by the Na-doped OMS-2, and finally the K-doped OMS-2. Our studies provide detailed insights into the interactions between cations and OMS-2 and the $\mathrm{CO}_{2}$ sorption performance of OMS-2. The results reveal that $\mathrm{CO}_{2}$ uptake capacity and sorption hysteresis can be optimized by changing the cations accommodated in the porous materials, which is important to develop effective and efficient $\mathrm{CO}_{2}$ capture and storage materials.

\section{Acknowledgments}

This work was partially funded by the NIST-ARRA fellowship. The authors would like to thank Eric Cockayne, Laura Espinal, and Winnie Wong-Ng at NIST for computational and experimental consultations. The calculations in this paper were performed on the high-performance computing systems at Idaho National Lab and Boise State University. 
Table 1. Effect of cation on the structural features of $\alpha$-MnO2, including lattice parameters $(\AA)$ and cell volume $\left(\AA^{3}\right)$.

\begin{tabular}{|c|c|c|c|c|c|c|}
\hline & \multicolumn{3}{|c|}{ 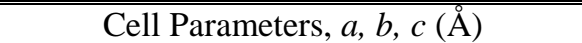 } & Volume $\left(\AA^{3}\right)$ & \multicolumn{2}{|c|}{ "Bond length $(\AA)$} \\
\hline Pure $\mathrm{Mn}_{24} \mathrm{O}_{48}$ & 9.702 & 8.568 & 9.685 & 805.04 & & \\
\hline With Cation & & & & & Cation-Mn & Cation-O \\
\hline $\mathrm{K}^{+}$ & 9.702 & 8.554 & 9.731 & 807.48 & 3.57 & 2.85 \\
\hline $\mathrm{Na}^{+}$ & 9.678 & 8.555 & 9.706 & 803.63 & 3.55 & 2.82 \\
\hline $\mathrm{Ba}^{2+}$ & 9.713 & 8.542 & 9.735 & 807.64 & 3.59 & 2.83 \\
\hline
\end{tabular}

Table 2. Effect of $\mathrm{CO}_{2}$ sorption on the structural features of $\alpha-\mathrm{MnO}_{2}$, including lattice parameters $(\AA)$ and cell volume $\left(\AA^{3}\right)$

\begin{tabular}{lccccc}
\hline \hline \multicolumn{3}{c}{ Cell Parameters, $a, b, c(\AA)$} & Volume $\left(\AA^{3}\right)$ & $\begin{array}{l}\text { Volume } \\
\text { Change }\end{array}$ \\
\hline Pure $\mathrm{Mn}_{24} \mathrm{O}_{48}$ & 9.702 & 8.568 & 9.685 & 805.04 & -- \\
\hline With Cation and $\mathrm{CO}_{2}$ Adsorption & & & & \\
$\mathrm{KMn}_{24} \mathrm{O}_{48}+\mathrm{CO}_{2}$ & 9.797 & 8.545 & 9.712 & 813.06 & $1.00 \%$ \\
$\mathrm{NaMn}_{24} \mathrm{O}_{48}+\mathrm{CO}_{2}$ & 9.735 & 8.557 & 9.725 & 810.13 & $0.63 \%$ \\
$\mathrm{BaMn}_{24} \mathrm{O}_{48}+\mathrm{CO}_{2}$ & 9.747 & 8.536 & 9.769 & 812.83 & $0.97 \%$ \\
\hline \hline
\end{tabular}

Table 3. Summary of three $\mathrm{CO}_{2}$ diffusion mechanisms for corresponding cations

\begin{tabular}{|c|c|c|c|}
\hline & Scenario I & Scenario II & Scenario III \\
\hline K-doped OMS-2 & $\checkmark$ & $\checkmark$ & $\checkmark$ \\
\hline Na-doped OMS-2 & $\checkmark$ & & \\
\hline Ba-doped OMS-2 & $\checkmark$ & & \\
\hline
\end{tabular}
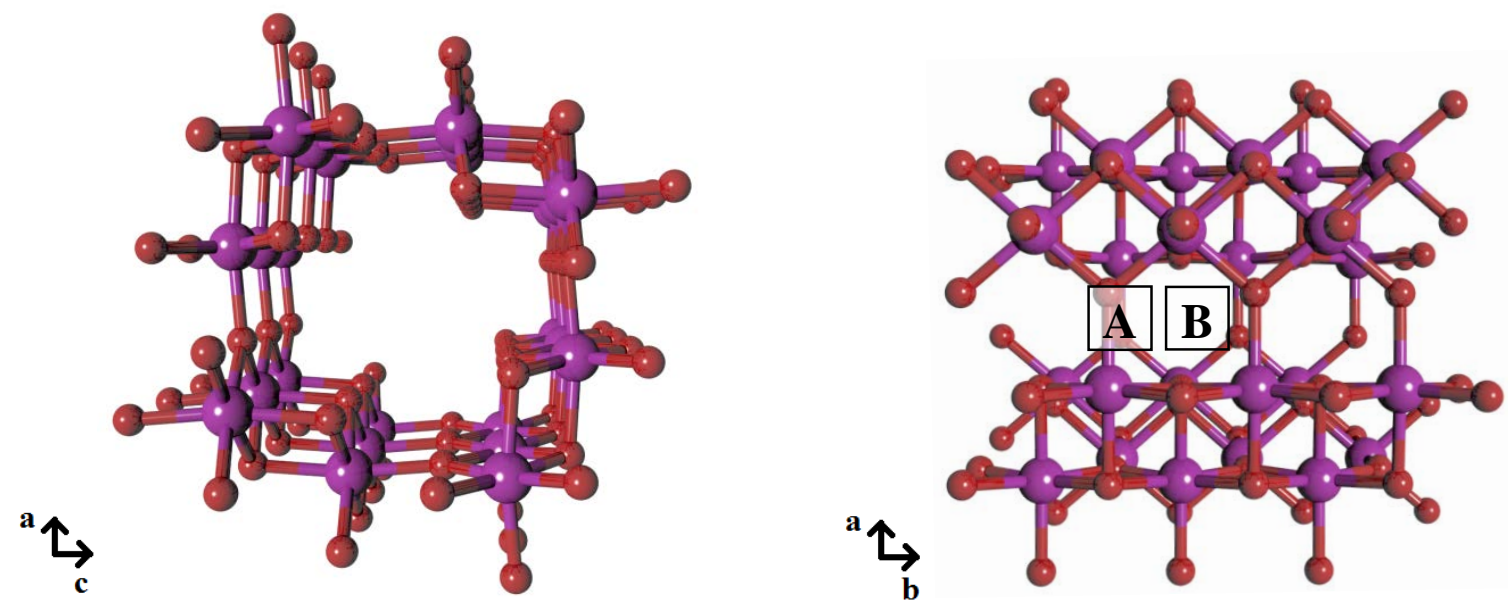

Fig. 1 Different views of a crystal structure of $\alpha-\mathrm{MnO}_{2}$, where $\mathrm{Mn}$ is purple, and $\mathrm{O}$ is red. The $(2 \times 2)$ tunnel is along the $b$ axis. Sites A and B are two high-symmetry positions. 
(a)

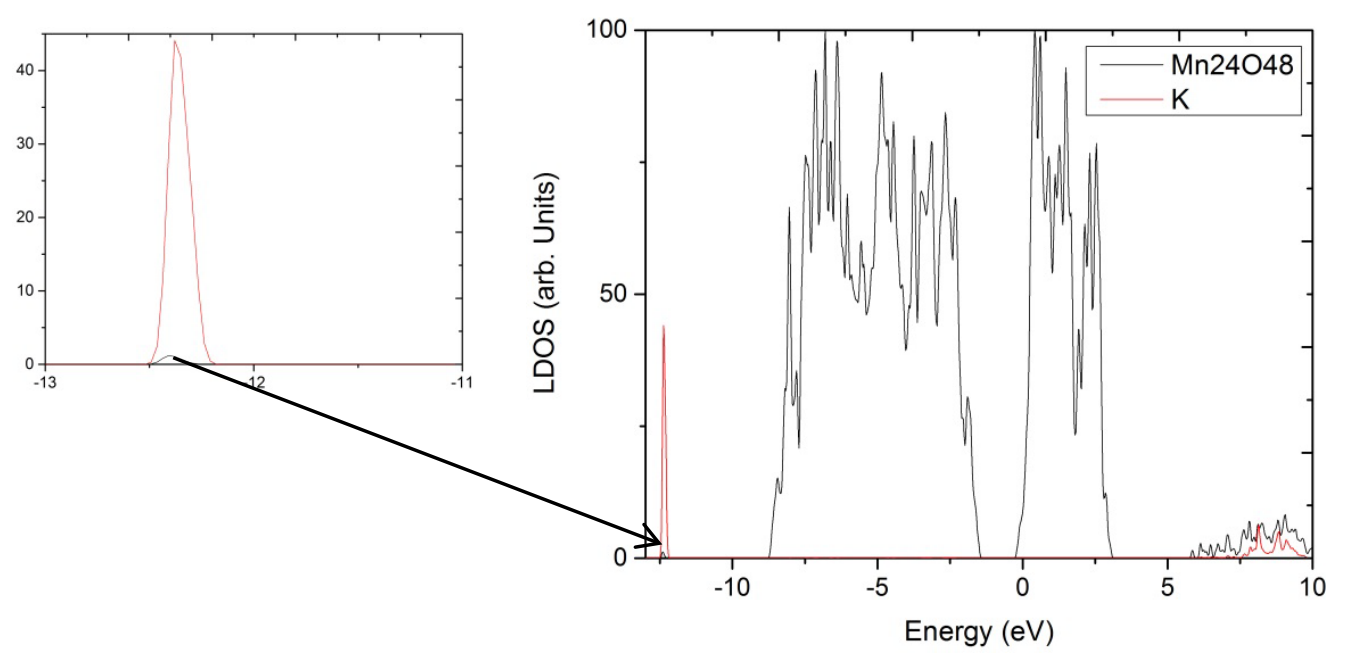

(b)

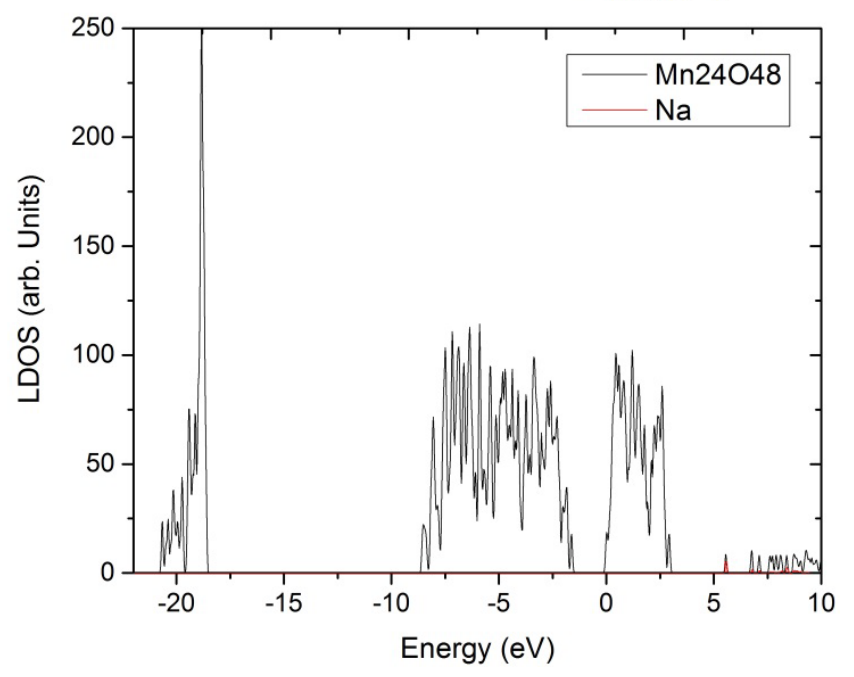

(c)

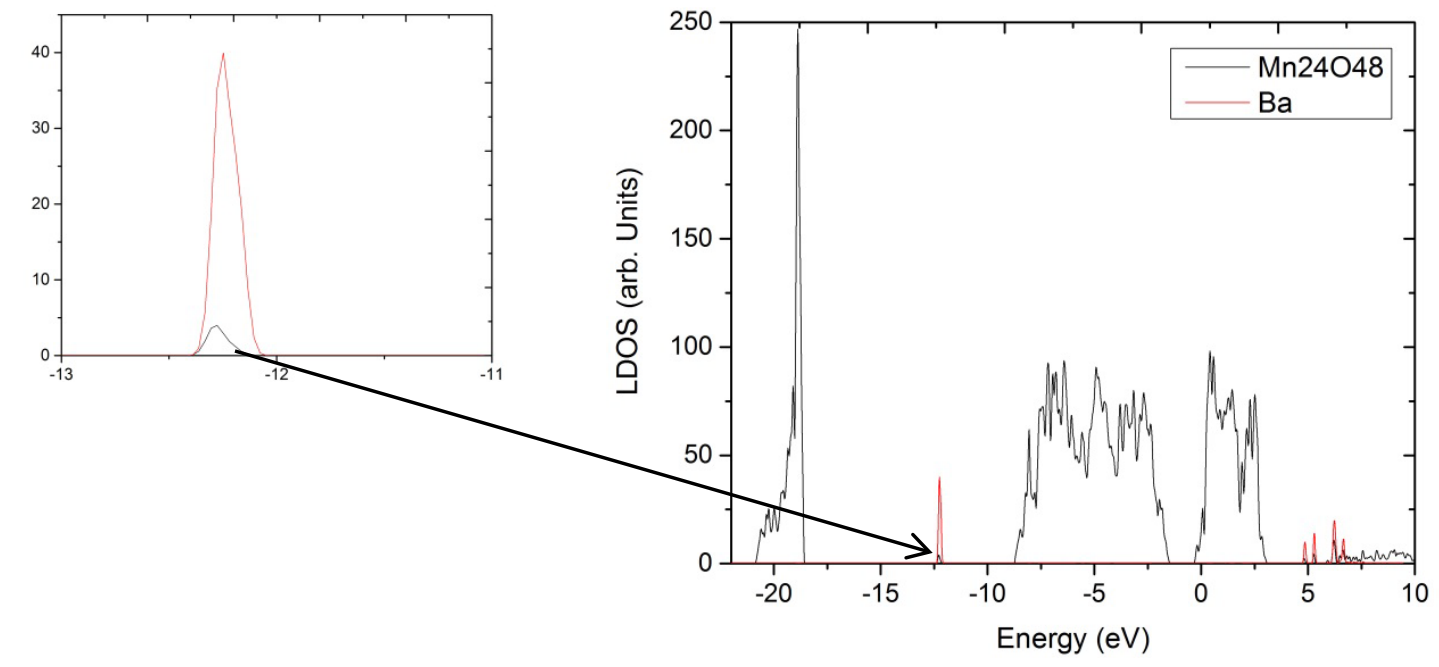


(d)

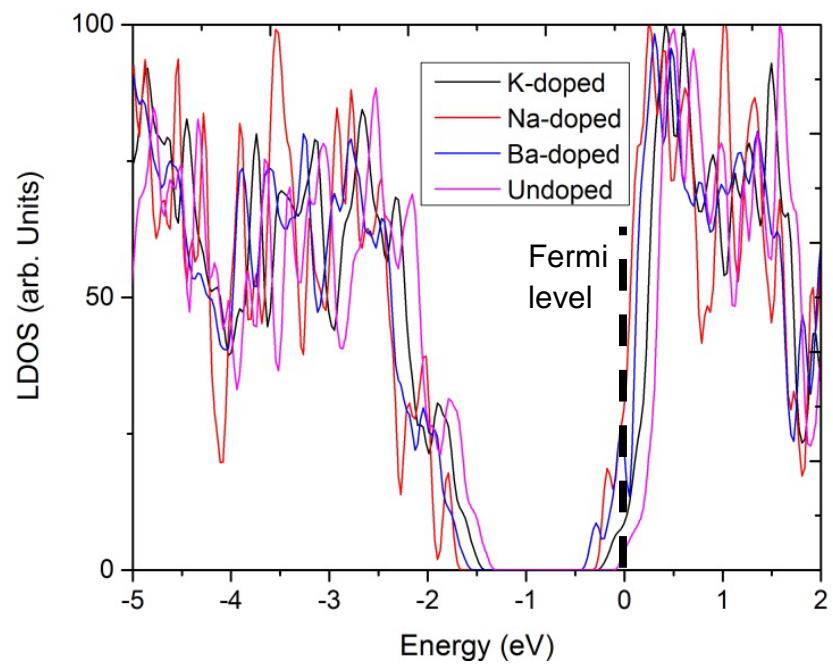

Fig. 2 Density of states (DOS) for doped and undoped $\alpha-\mathrm{MnO}_{2}$. (a)-(c) DOS projected on $\alpha-\mathrm{MnO}_{2}, \mathrm{~K}, \mathrm{Na}$, and $\mathrm{Ba}$ individually; and (d) DOS comparison before and after doping in $\alpha-\mathrm{MnO}_{2}$.

(a)

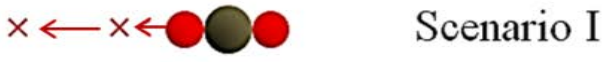

(b)

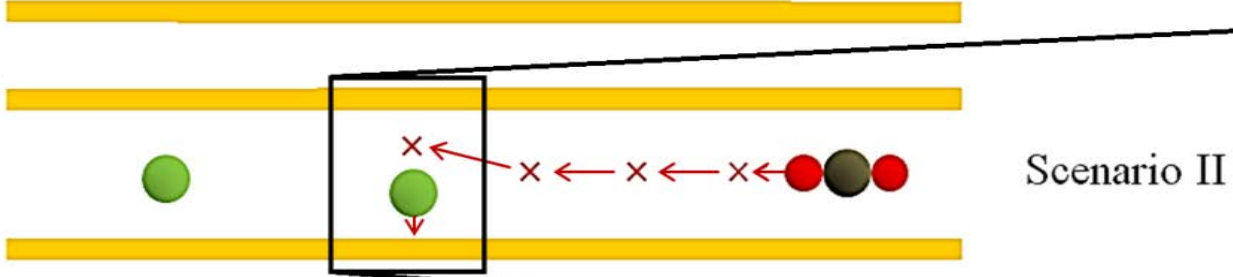

(c)

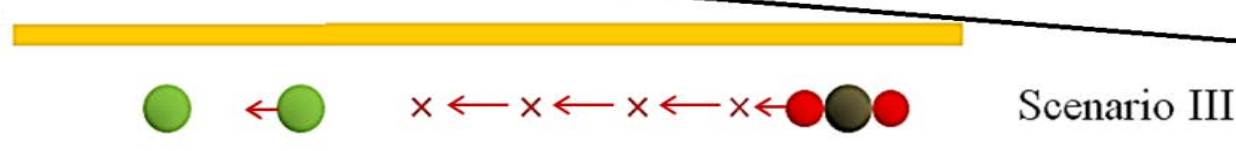

Fig. 3 Three possible diffusion mechanisms for $\mathrm{CO}_{2}$ in an OMS-2 $(2 \times 2)$ tunnel: red, O; black, C; green, cation $\left(\mathrm{K}^{+}\right.$, $\mathrm{Na}^{+}$, or $\mathrm{Ba}^{2+}$ ); red cross, corresponding $\mathrm{CO}_{2}$ position; red arrow, diffusion direction. For clarity, yellow walls highlight the location of the $\mathrm{MnO}_{2}$ (tunnel walls). (a) $\mathrm{CO}_{2}$ remains an optimum distance from the cation (Scenario I); (b) $\mathrm{CO}_{2}$ bypasses a cation while the cation shifts towards the porous surface (Scenario II), the insert depicts the transition state in the OMS-2 tunnel where the $\mathrm{CO}_{2}$ molecule sits alongside the cation and the O-C-O angle is distorted to $134.5^{\circ}$ (foreground atoms removed for clarity); and (c) $\mathrm{CO}_{2}$ pushes a cation to diffuse (Scenario III). There is an activation energy barrier associated with the formation of the transition state in Scenario II and a diffusion energy barrier for the $\mathrm{CO}_{2}$ to push the cation in Scenario III. 


\section{References}

[1] S. Chu, Science 325 (2009) 1599.

[2] Y. Cui, H. Kita, K. Okamoto, Chem Commun 17 (2003) 2154.

[3] Q.L. Liu, A. Mace, Z. Bacsik, J.L. Sun, A. Laaksonen, N. Hedin, Chem Commun 46 (2010) 4502.

[4] J.R. Li, R.J. Kuppler, H.C. Zhou, Chem Soc Rev 38 (2009) 1477.

[5] L.C. Lin, K. Lee, L. Gagliardi, J.B. Neaton, B. Smit, J Chem Theory Comput 10 (2014) 1477.

[6] J.R. Li, Y.G. Ma, M.C. McCarthy, J. Sculley, J.M. Yu, H.K. Jeong, P.B. Balbuena, H.C. Zhou, Coordin Chem Rev 255 (2011) 1791.

[7] D. Britt, H. Furukawa, B. Wang, T.G. Glover, O.M. Yaghi, P Natl Acad Sci USA 106 (2009) 20637.

[8] L. C. Lin, A. H. Burger, R. L. Martin, J. Kim, J. A. Swisher, K. Jariwala, C. H. Rycroft, A. S. Bhown, M. W. Deem, M. Haranczyk, B. Smit, Nat Mater 11 (2012) 633.

[9] L. Li, E. Cockayne, I. Williamson, L. Espinal, W. Wong-Ng, Chem Phys Lett 580 (2013) 120.

[10] Z.B. Bao, L.A. Yu, Q.L. Ren, X.Y. Lu, S.G. Deng, J Colloid Interf Sci 353 (2011) 549.

[11] Z.R. Herm, R. Krishna, J.R. Long, Micropor Mesopor Mat 157 (2012) 94.

[12] J. Seo, D. Whang, H. Lee, S. Jun, J. Oh, Y. Jeon, K. Kim, Nature 404 (2000) 982.

[13] A.J. Brown, N.A. Brunelli, K. Eum, F. Rashidi, J.R. Johnson, W.J. Koros, C.W. Jones, S. Nair, Science 345 (2014) 72.

[14] J. Gascon, F. Kapteijn, B. Zornoza, V. Sebastián, C. Casado, J. Coronas, Chem. Mater. 24 (2012) 2829.

[15] H. Li, M. Eddaoudi, M. O'Keeffe, O.M. Yaghi, Nature 402 (1999) 276.

[16] K.G. Ray, D.L. Olmsted, J.M.R. Burton, Y. Houndonougbo, B.B. Laird, M. Asta, Chem Mater 26 (2014) 3976.

[17] P. Canepa, C.A. Arter, E.M. Conwill, D.H. Johnson, B.A. Shoemaker, K.Z. Soliman, T. Thonhauser, J Mater Chem A 1 (2013) 13597.

[18] P. Canepa, N. Nijem, Y.J. Chabal, T. Thonhauser, Phys Rev Lett 110 (2013) 026102.

[19] C. Lastoskie, K.E. Gubbins, N. Quirke, J Phys Chem-Us 97 (1993) 4786.

[20] D.L. Bish, J.E. Post, Am Mineral 74 (1989) 177.

[21] R.N. Deguzman, Y.F. Shen, E.J. Neth, S.L. Suib, C.L. O'young, S. Levine, J.M. Newsam, Chem Mater 6 (1994) 815.

[22] S.L. Suib, Accounts Chem Res 41 (2008) 479.

[23] W. Morris, N. He, K.G. Ray, P. Klonowski, H. Furukawa, I.N. Daniels, Y.A. Houndonougbo, M. Asta, O.M. Yaghi, B.B. Laird, Journal of Physical Chemistry C 116 (2012) 24084.

[24] X. Chen, Y.F. Shen, S.L. Suib, C.L. O'Young, J Catal 197 (2001) 292.

[25] S.L. Suib, J Mater Chem 18 (2008) 1623.

[26] L. Espinal, W. Wong-Ng, J.A. Kaduk, A.J. Allen, C.R. Snyder, C. Chiu, D.W. Siderius, L. Li, E. Cockayne, A.E. Espinal, S.L. Suib, J Am Chem Soc 134 (2012) 7944.

[27] A. Bystrom, A.M. Bystrom, Acta Crystallogr 3 (1950) 146.

[28] G. Kresse, J. Furthmuller, Phys Rev B 54 (1996) 11169.

[29] J.P. Perdew, A. Ruzsinszky, G.I. Csonka, O.A. Vydrov, G.E. Scuseria, L.A. Constantin, X.L. Zhou, K. Burke, Phys Rev Lett 100 (2008) 136406.

[30] P.E. Blochl, Phys Rev B 50 (1994) 17953.

[31] G. Kresse, D. Joubert, Phys Rev B 59 (1999) 1758.

[32] A.I. Liechtenstein, V.I. Anisimov, J. Zaanen, Phys Rev B 52 (1995) R5467.

[33] Y. Paik, J.P. Osegovic, F. Wang, W. Bowden, C.P. Grey, Journal of the American Chemical Society 123 (2001) 9367.

[34] E. Cockayne, L. Li, Chem Phys Lett 544 (2012) 53.

[35] S. Grimme, Journal of computational chemistry 27 (2006) 1787.

[36] H. Wu, J.M. Simmons, G. Srinivas, W. Zhou, T. Yildirim, J Phys Chem Lett 1 (2010) 1946.

[37] M.K. Rana, H.S. Koh, J. Hwang, D.J. Siegel, Journal of Physical Chemistry C 116 (2012) 16957.

[38] A. Iyer, H. Galindo, S. Sithambaram, C. King’ondu, C.-H. Chen, S.L. Suib, Applied Catalysis A: General 375 (2010) 295.

[39] T. Gao, M. Glerup, F. Krumeich, R. Nesper, H. Fjellvag, P. Norby, J. Phys. Chem. C 112 (2008) 13134.

[40] J. Lan, D. Cao, W. Wang, B. Smit, ACS Nano 4 (2010) 4225.

[41] H. Pfeiffer, C. Vázquez, V.H. Lara, P. Bosch, Chem. Mater. 19 (2007) 922. 